\title{
Morphogenesis in Drosophila requires nonmuscle myosin heavy chain function
}

\author{
Paul E. Young, Adam M. Richman, Andrew S. Ketchum, and Daniel P. Kiehart ${ }^{1,2}$ \\ Department of Cellular and Developmental Biology, Harvard Biological Laboratories, Harvard University, Cambridge, \\ Massachusetts 02138 USA; and ${ }^{1}$ Department of Cell Biology, Duke University Medical Center, \\ Durham, North Carolina 27710 USA
}

\begin{abstract}
We provide the first link between a known molecular motor and morphogenesis, the fundamental process of cell shape changes and movements that characterizes development throughout phylogeny. By reverse genetics, we generate mutations in the Drosophila conventional nonmuscle myosin (myosin II) heavy chain gene and show that this gene is essential. We demonstrate that these mutations are allelic to previously identified, recessive, embryonic-lethal zipper mutations and thereby identify nonmuscle myosin heavy chain as the zipper gene product. Embryos that lack functional myosin display defects in dorsal closure, head involution, and axon patterning. Analysis of cell morphology and myosin localization during dorsal closure in wild-type and homozygous mutant embryos demonstrates a key role for myosin in the maintenance of cell shape and suggests a model for the involvement of myosin in cell sheet movement during development. Our experiments, in conjunction with the observation that cytokinesis also requires myosin, suggest that the processes of cell shape change in morphogenesis and cell division are intimately and mechanistically related.
\end{abstract}

[Key Words: Drosophila; morphogenesis; myosin heavy chain function; zipper gene product]

Received July 14, 1992; revised version accepted November 4, 1992.

The development of metazoan form is characterized by complex cell shape changes and cell sheet movements, whose molecular basis has not been established. A number of studies suggest a key role for the cytoskeleton, the cell surface, and the extracellular matrix in morphogenesis (for review, see Armstrong 1985; Ettensohn 1985; Fristrom 1988; Fessler and Fessler 1989). To date, the most compelling evidence that microfilaments participate in these developmental processes comes from pharmacological studies. For example, cytochalasins can disrupt global morphological changes during neural tube formation in vertebrates (e.g., Burnside 1971), embryo elongation in nematodes (Priess and Hirsh 1986), and epiboly in teleosts (Betchaku and Trinkaus 1978). In addition, these drugs abolish neurite elongation and the establishment of neuron polarity-extreme examples of individual cell shape changes (e.g., Letourneau et al. 1987). Such studies suggest that a detailed understanding of morphogenesis will require a catalog of the molecular motors responsible for cell movement and cell shape change, the molecular switches that regulate the function of such motors, and the cytoskeletal elements with which they interact to produce and transmit force.

Myosins are molecular motors with widespread expression in both muscle and nonmuscle cells where they participate in diverse processes. Conventional myosins (myosins II) are molecular motors composed of two iden-

${ }^{2}$ Corresponding author. tical heavy chains and two pairs of light chains (Warrick and Spudich 1987; Korn and Hammer 1988; Spudich 1989; Kiehart 1990; Kiehart et al. 1990). Myosin heavy chains, in concert with a filamentous actin substrate, alone may be sufficient for chemomechanical force production, whereas the light chain subunits apparently function to regulate and modify heavy chain activity. Nonmuscle (or cytoplasmic) myosins II are required for cytokinesis in dividing cells: Microinjection of anti-myosin II antibody blocks cytokinesis in echinoderms (Mabuchi and Okuno 1977; Kiehart et al. 1982), gene disruption and antisense experiments show that myosin II is required for cytokinesis in Dictyostelium (De Lozanne and Spudich 1987; Knecht and Loomis 1987; for review, see Spudich 1989), and a mutation in the nonmuscle myosin regulatory light chain [spaghetti-squash $(s q h)]$ blocks cytokinesis in Drosophila (Karess et al. 1991). However, in metazoans, myosins II are also conspicuous components of postmitotic cells, suggesting that there are key roles for this protein beyond its contribution to cell division. Antibody microinjection experiments in Drosophila, for example, demonstrate that myosin II may participate in nuclear migration and in the maintenance of the cell (embryo) cortex (Kiehart et al. 1990; D. Lutz and D.P. Kiehart, unpubl.). In addition, studies on lower eukaryotes have shown that conventional myosin is required for nuclear migration in yeast (Watt et al. 1987) and for the distribution of cell-surface receptors and development in Dictyostelium (Spudich 19891 . 
We have focused on the role of nonmuscle myosin in cell shape changes during Drosophila development. Previously, we purified native nonmuscle myosin II from Drosophila (Kiehart and Feghali 1986) and cloned and sequenced the genes encoding each of its component polypeptides (Kiehart et al. 1989; Ketchum et al. 1990; Karess et al. 1991; K.A. Edwards, X.-J. Chang, and D.P. Kiehart, unpubl.). We showed that embryos receive a substantial contribution of maternal myosin heavy chain and analyzed the localization of myosin in developing embryos (Young et al. 1991). We found that the localization of myosin in the early embryo changes dramatically: Myosin is recruited to the cell cortex, presumably to contribute to cytokinesis (cellularization), and is found specifically at the apical ends of epithelial cells that undergo apical constrictions during cell sheet invagination in early gastrulation (Kiehart et al. 1990; Young et al. 1991). These changes in myosin distribution occur before a peak of myosin transcript and protein accumulation from 4 to $12 \mathrm{hr}$ after egg laying, suggesting that early movements that require myosin may be powered by myosin from maternal stores. Zygotically encoded myosin presumably contributes to cellular and developmental processes that occur later in development.

Here, we demonstrate genetically that nonmuscle myosin is essential and is encoded by the zipper (zip) locus. We focus our efforts on defects that occur in homozygous myosin mutants during dorsal closure and demonstrate that cell shapes are aberrant in these mutants. These data indicate that nonmuscle myosin is required for generating or maintaining, or both, the cell shapes that change during the course of morphogenesis; provide a link between myosin, a known chemomechanical, force-producing protein or motor, and morphogenesis; and suggest a simple model in which myosin contributes locally to changes in cell shape to drive cell sheet morphogenesis. Finally, observations that both cytokinesis and morphogenesis require the same motor protein suggest that the two processes are mechanistically related.

\section{Results}

Mutations in nonmuscle myosin: the zipper locus encodes the nonmuscle myosin heavy chain

We generated a number of ethylmethane sulfonate (EMS)-induced mutations in the myosin heavy chain gene, all of which result in a failure to complete normal development (for details, see Materials and methods). The most severe alleles are embryonic lethal when present over a deficiency that removes the myosin heavy chain gene. These mutations also fail to complement previously identified zip mutations (Nüsslein-Volhard et al. 1984). One of our myosin heavy chain alleles zip $p^{\text {mhc-c1.3 }}$ produces an electrophoretically variant myosin heavy chain polypeptide (Fig. 1A): On immunoblots of heterozygous adults, the mutant species is less abundant than the wild-type myosin and migrates with an apparent molecular mass of $195-\mathrm{kD}$, just ahead of the $205-\mathrm{kD}$ wild-type nonmuscle myosin heavy chain. Inter-

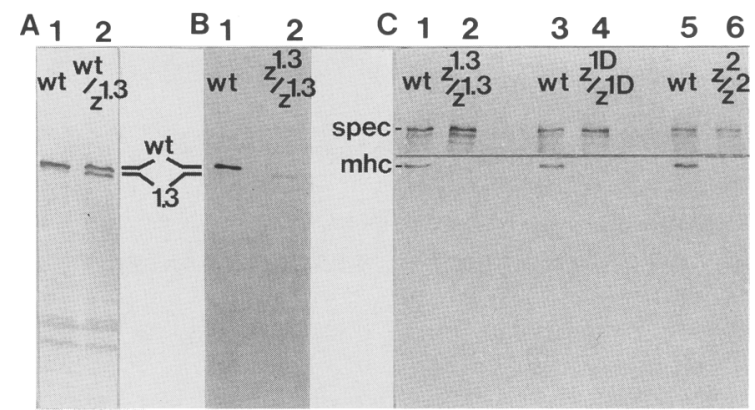

Figure 1. Immunoblots identify a complementation group with defects in myosin heavy chain. Immunoblots demonstrate that $z i p^{m h c-c 1.3}$ produces an electrophoretically variant myosin heavy chain polypeptide, and both zip ${ }^{I I F 107}$ and $z i p^{I D 16}$ contain negligible levels of myosin polypeptide. Proteins in whole fly or embryo homogenates were resolved by SDS-PAGE and blotted to nitrocellulose. (A) An immunoblot of whole heterozygous fly homogenates, probed with anti-nonmuscle myosin antiserum: (Lane 1) $d p \mathrm{cn} b w / S M 6 a$ [wild type (wt) for nonmuscle myosin] (lane 2) zip ${ }^{m h c-c 1.3} / S M 6 a\left(\mathrm{wt} / \mathrm{z}^{1.3}\right)$. The normal $205-\mathrm{kD}$ myosin band in lanes 1 and 2 is encoded by the wild-type nonmuscle myosin genes present on the $d p c n b w$ (parental line) and the SM6a balancer chromosomes; the 195-kD band is encoded by the $d p$ cn $b w$ zip mhc-c1.3 $^{\text {chromosome. }}(B)$ An immunoblot of homozygous embryo homogenates, prepared $\sim 16 \mathrm{hr}$ after fertilization and probed with anti-nonmuscle myosin antiserum:

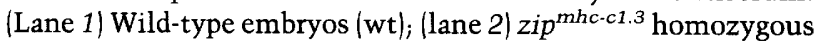
embryos $\left(z^{1.3} / z^{1.3}\right)$. (C) An immunoblot of homozygous embryo homogenates, prepared from three different zip alleles $\sim 24 \mathrm{hr}$ after fertilization. Larvae that are wild type for some myosin function have hatched from eggs by this time in development, and the abnormal morphology of homozygous zip embryos distinguishes them from embryos of the double-balancer chromosome class $(S M 6 a / S M 6 a)$. The lower portion of this immunoblot has been probed with anti-nonmuscle myosin antiserum (mhc); the upper portion of the immunoblot has been probed with anti-spectrin antiserum (spec), which demonstrates equivalent loading and lack of proteolysis in homozygous mutant samples. (Lane 1) SM6a/SM6a unhatched embryos ( wt); (lane 2) $z i p^{\text {mhc-c1.3 }}$ homozygous embryos $\left(z^{1.3} / z^{1.3}\right.$; (lane 3) zip $p^{I D 16} / S M 6 a$ and/or SM6a/SM6a embryos, wild-type (wt) for some myosin functions; (lane 4) zip ${ }^{I D 16}$ homozygous embryos $\left(z^{1 D} / z^{1 D}\right)$; (lane 5) $z_{i p}{ }^{I I F 107} / S M 6 a$ and/or SM6a/SM6a embryos, wild type (wt) for some myosin function; (lane 6) zip ${ }^{I I F 107}$ homozygous embryos $z^{2} / z^{2}$.

estingly, the $z i p^{m h c-c 1.3}$ myosin polypeptide is also visible in homozygotes (Fig. IB), where it appears even less abundant, suggesting that an interaction between the mutant polypeptide and the wild-type form stabilizes this mutant protein. Two of the original zip alleles (Nüsslein-Volhard et al. 1984; Côté et al. 1987) appear to produce reduced levels of myosin (Fig. 1C): both zip ${ }^{I I F 107}$ and zip ${ }^{I D 16}$ embryo homogenates have barely detectable levels of myosin heavy chain polypeptide.

To characterize more completely the molecular lesions responsible for the zip mutations, we analyzed genomic DNA isolated from heterozygous zip flies. We found no differences in the pattern of Southern blots probed with nonmuscle myosin cDNAs, suggesting that there were no gross rearrangements of DNA in any of the 
myosin alleles recovered thus far (data not shown). To analyze the molecular lesion responsible for the high mobility myosin that characterizes the $z^{\text {inhc-c1.3 }}$, we sequenced polymerase chain reaction (PCR) product derived from genomic template at the $3^{\prime}$ end of the mutant myosin-coding region. A premature stop codon that results from a CG $\rightarrow$ TA base-pair substitution/changing a CAG triplet that encodes glutamine to a TAG amber stop codon), truncates this mutant myosin heavy chain 77 amino acids upstream of the wild-type carboxyl terminus (data not shown). This molecular defect is appropriate to explain the higher mobility of the $z i p^{\text {mhc-c1.3 }}$ myosin heavy chain polypeptide.

To verify that the zip mutations are the result of defects in the gene encoding the nonmuscle myosin heavy chain polypeptide, we rescued the mutant phenotype with P-element-mediated germ-line transformation /to date, two alleles, zip $p^{m h c-c 1.3}$ and $z i p^{I I F 107}$, have been tested and rescued). The embryonic lethal phenotype of homozygous mutant embryos is abolished, with expected Mendelian frequency, when wild-type myosin heavy chain transcription is induced from a transgenic, full-length myosin heavy chain cDNA driven by an $h s p 70$ promoter ( $\left.\mathrm{p}\left[h s-m h c-c^{1}\right]\right)$. Rescued embryos arrest during larval development if there is no further induction of myosin heavy chain transcription. However, an appropriate regimen of induction by intermittent heat shocks administered throughout development permits a low number $(\sim 5 \%$ of expected Mendelian frequency) of homozygous zip mutants that carry the $\mathrm{p}\left[h s-m h c-c^{1}\right]$ construct to reach adulthood. A P-element cosmid construct that spans the entire genomic transcription unit of the nonmuscle myosin heavy chain can completely rescue (with expected Mendelian frequency) these homozygous zip mutant individuals to adulthood.

Together with molecular and genetic mapping experiments (data not shown; see also Lindsley and Zimm 1992, p. 797), these studies prove formally that zip encodes the nonmuscle myosin heavy chain. By historical precedent, all mutations in the nonmuscle myosin heavy chain will be designated using the zip nomenclature (e.g., $z i p^{I F 107}, z i p^{m h c-c 1.3}$ ). In this paper, we focus on an analysis of the phenotype of zip mutations as revealed by the alleles zip ${ }^{\text {mhc-c1.3 }}$ and zip ${ }^{I I F 107}$. We have also identified six other zip alleles-four that are embryonic lethal $\left(z i p^{m h c-c 1.6}, z^{\text {mhhc-c3.9 }}, z^{\text {mhhc-c3.12 }}\right.$, and $\left.z i p^{\text {mhc-c14 }}\right)$ and two that arrest during later stages, before eclosion $\left(z i p^{m h c-c 2.1}\right.$ and $\left.z i p^{m h c-c 6.1}\right)$.

\section{Myosin mutants have defects in cell sheet morphogenesis and myosin localization}

Previous analysis of larval cuticles suggested that homozygous zip embryos have several defects in normal morphogenesis (Nüsslein-Volhard et al. 1984), the earliest and most conspicuous of which occurs during dorsal closure (Fig. 2; for a detailed description of dorsal closure, see Campos-Ortega and Hartenstein 1985). This defect is manifest by a prominent, irregularly shaped dorsal opening in the cuticle at later stages of embryonic devel- opment (Nüsslein-Volhard et al. 1984; Côté et al. 1987). It occurs because the columnar cells of the lateral epidermis fail to cover completely the flat amnioserosal cells, which do not secrete cuticle (for orientation, see Fig. 2). Because the dorsal-most edge of the epidermal cells leads the advance of the lateral epidermis over the amnioserosa, we refer to it as the leading edge (Fig. 2), and the cells that include it, the cells of the leading edge.

To better understand the phenotype of failure in zip mutants, we have examined both nonmuscle myosin localization and cell shapes (as ascertained by antispectrin staining of embryos). In wild-type embryos, the onset of dorsal closure is heralded by a specific subplasmalemma accumulation of nonmuscle myosin II at the leading edge of the lateral epidermis (Fig. 3, arrows). In addition, the overall level of myosin in the cytoplasm of the cells of the leading edge is increased (Fig. 3, arrowheads). The subplasmalemma accumulation of myosin at the leading edge appears as a "purse string" (Fig. 3C, arrows) that delimits the dorsal opening over the amnioserosa.

In the leading edge of wild-type embryos, cells are tightly organized and their shapes are highly ordered, such that the entire lateral epidermal cell sheet presents a smooth front as it advances over the dorsal surface of the embryo (Fig. 4A,B). The maintenance of the integrity and the organization of the leading edge appears to ensure the proper alignment of each flank of the lateral epidermis so that they can contact and fuse along the dorsal midline (Fig. 4B).

Embryos homozygous for severe (embryonic lethal) zip alleles have a nearly normal distribution of myosin early in dorsal closure that becomes aberrant by later stages of dorsal closure. At the beginning of dorsal closure, the wild type distribution of myosin, with specific subcellular localization at the leading edge, is maintained in homozygous zip embryos but at much reduced levels (Fig. 5). zip ${ }^{I I F 107}$ homozygous embryos (which appear to be null or near null, on the basis of protein levels revealed on immunoblots, see Fig. 1) have virtually no zygotically encoded myosin; therefore, we assume that the great majority of myosin present in zip embryos at this time is maternally contributed, wild-type myosin that perdures into the early stages of dorsal closure. In contrast, by late dorsal closure stages, nonmuscle myosin is improperly localized in or absent from, the leading edge in an allele

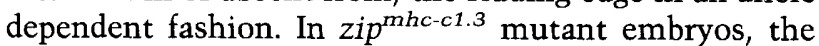
specific accumulation of myosin at the leading edge is completely abolished, however, as in wild type embryos, we still observe diffuse myosin (presumably the truncated form) in the cytoplasm of cells of the leading edge that is more abundant than in other cells of the lateral epidermis (Fig. 6A, B). In zip ${ }^{I I F 107}$ mutant embryos, both the myosin accumulation at the leading edge and the diffuse cytoplasmic myosin staining in cells of the leading edge are absent during late dorsal closure stages (data not shown|. Generally, zip ${ }^{m h c-c 1.3}$ embryos complete more of dorsal closure than do zip ${ }^{I I F 107}$ embryos, which has a phenotype comparable with that observed for $D f(2 R) E S 1 / D f(2 R) I I X 62$ (overlapping deficiencies that completely remove and break in the myosin gene, re- 
Figure 2. Morphogenesis during dorsal closure requires movement of lateral epidermal sheets. $(A) \mathrm{A}$ confocal fluorescent micrograph of a whole-mount wild-type Drosophila embryo, fixed and stained with anti-spectrin antiserum. The spectrin labeling provides a marker for cell boundaries and establishes the pattern of cell shape changes during dorsal closure. The stage of this embryo is roughly comparable with the diagram in $B .\left(B, B^{\prime}\right)$ Sketches of wild-type Drosophila embryos at two stages during dorsal closure. $\mid C$, $\left.C^{\prime}\right)$ Magnified sketch of the cells at the earlier and later dorsal closure stages, respectively, based on the scanning confocal micrographs shown in Fig. 8. $1 D$, $\left.D^{\prime}\right)$ Magnified view of the apical end of one cell of the lateral epidermis with a schematic of how myosin thick filaments and actin filaments might be arranged to drive apical constriction during dorsal closure. The junctions shown indicate that the cells at the leading edge are mechanically linked and are not meant to indicate specific molecular or morphological features of the interconnections between cells. $B$ was produced and generously provided by V. Hartenstein, University of California, Los Angeles; $B^{\prime}$ was modified from another of his drawings. $B-D^{\prime}$ were all generated using Adobe Illustrator software on a MacIntosh IIfx computer. For all panels, anterior is to the left; dorsal is to the top. (as) Amnioserosa; (le) leading edge of the lateral epidermis; (lat) lateral epidermis; (my) myosin thick filaments; (act) actin-containing thin filaments. Hash marks on actin filament indicate sites at which the polarity of the filament must change to interact with the myosin filaments diagramed. Arrows in $B$ indicate the relative movement of the lateral epidermis during dorsal closure. Bar, 25 $\mu \mathrm{m}(A)$.
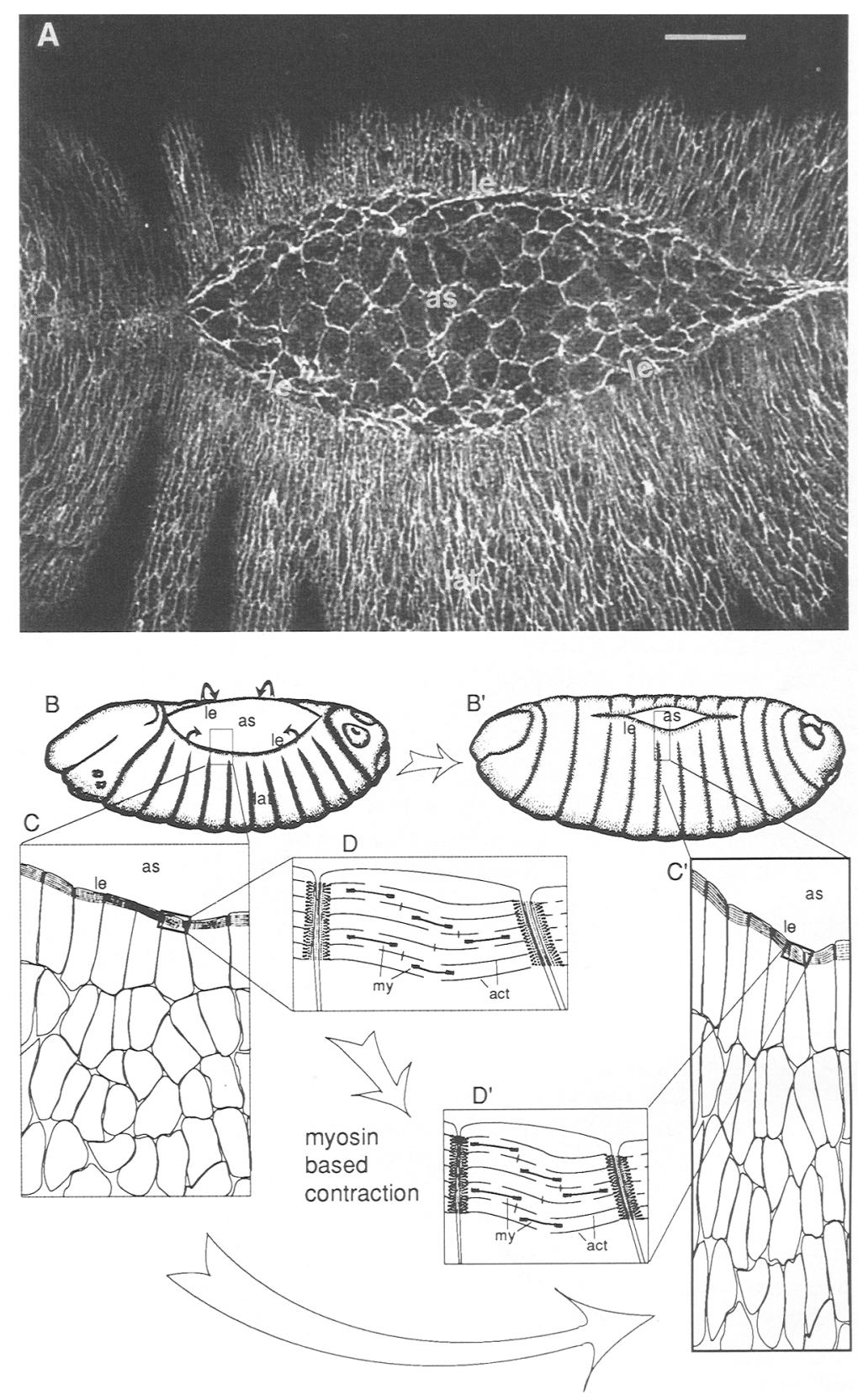

spectively), and to zip ${ }^{I D 16}$ (which genetically and protein-wise is null or null-like; Lindsley and Zimm 1992; see Fig. 1). However, the extent of dorsal closure is variable in mutant embryos of both alleles (e.g., compare the extent of dorsal closure in the embryos in Figs. 4 C,D and $6 \mathrm{C})$.

By the time homozygous zip mutant embryos arrest during late dorsal closure stages, the leading edge is dramatically disorganized, the lateral epidermis is not fused along the dorsal midline, and the amnioserosa remains exposed. The cell sheets are convoluted, buckled, and thrown up into folds that pass in and out of the image plane. This is particularly noticeable in the region occupied by the amnioserosa (Fig. 4C, D, arrowheads). More- over, individual cells of the leading edge are in disarray, irregularly shaped, and splayed apart (Fig. 4C, D, arrows).

To understand better the mechanism by which myosin might function in dorsal closure, we also examined the distribution of actin in wild type and homozygous zip embryos (Fig. 7). In wild-type embryos, actin and myosin colocalize: actin is present at a low level throughout the cytoplasm but is more concentrated at the leading edge of the lateral epidermis (Fig. 7A). The distribution of actin in homozygous zip embryos is indistinguishable from wild type (Fig. 7B). Together, these observations are consistent with dorsal closure being driven by an actomyosin contractile apparatus and the fact that the failure of dorsal closure in zip homozygotes is due specifically 

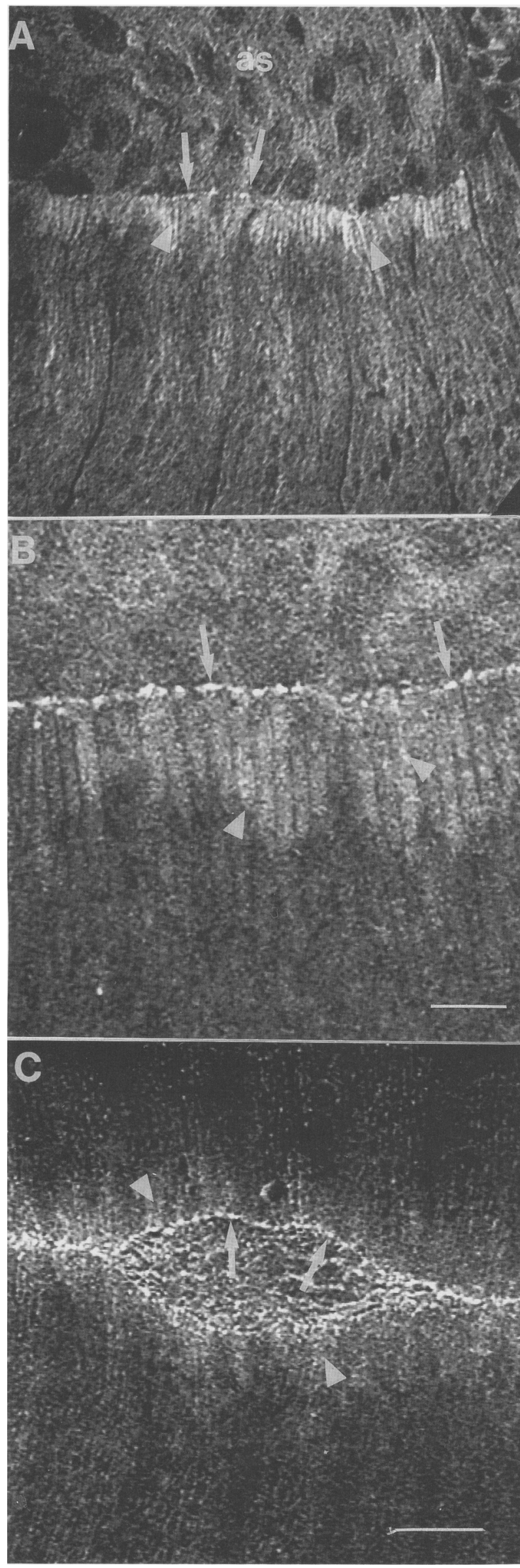

to the absence of myosin. The normal distribution of actin in zip homozygotes suggests that the overall structure of the cytoskeleton and the cell itself is not perturbed.

\section{The dynamics of cell shape changes during} dorsal closure

Our analysis of cell morphology during dorsal closure has focused on the cells of the leading edge, particularly at later stages of dorsal closure. It is in these cells and at these times of dorsal closure that there is an unambiguous, aberrant cell shape phenotype associated with zip homozygous mutant embryos. However, we have also documented the morphology of cells throughout dorsal closure in an attempt to understand and model this complex cell sheet movement.

During dorsal closure, the cells of the lateral epidermis undergo a dramatic cell shape change as the entire epidermal cell sheet thins out to spread over the amnioserosa. After germ-band retraction in normal embryos, all cells that comprise the ventral and lateral epidermis are polygonal in shape (not shown). At the beginning of dorsal closure, the cells of the leading edge are somewhat more elongated than those located more ventrally (Fig. $8 \mathrm{~A})$. As dorsal closure proceeds, more and more cells throughout the epidermis are elongated (Fig. 8B, C). Cells that are positioned adjacent to the leading edge appear to change shape before cells that are located more ventrally (Fig. 8B). As dorsal closure progresses, there is a reduction in the surface area of the amnioserosa visible in whole-mount embryo preparations, because the lateral epidermis moves over the amnioserosa as it shifts dorsally. Dorsal closure is complete when the apposing flanks of the lateral epidermis fuse along the dorsal midline.

This change in epidermal cell shape is sufficient to account for the spreading of the lateral epithelia over the region occupied by the amnioserosa. We measured the average dimensions of cells in embryos stained with an-

Figure 3. Myosin is at the leading edge of the lateral epithelium during dorsal closure. Confocal fluorescent micrographs of whole-mount, wild-type embryos, fixed and stained with antinonmuscle myosin antiserum show a general increase in the amount of myosin in cells of the leading edge and a specific targeting of myosin to the leading edge. $(A)$ An embryo in the early stages of dorsal closure. $(B)$ Higher magnification view of a similarly staged embryo. $(C)$ Dorsal view of an embryo fixed and stained for myosin during later stages of dorsal closure. In all panels, note the increased level of diffuse nonmuscle myosin in the cytoplasm of cells of the leading edge (arrowheads), as well as the specific accumulation of myosin at the leading edge in these same cells (arrows). Note how in $C$ the accumulation of myosin in each cell of the leading edge forms a continuous purse string of staining that defines the leading edge of the dorsal epidermis and surrounds the amnioserosa over which it is closing. (as) Amnioserosa. Bar, $25 \mu \mathrm{m}(A, C) ; 10 \mu \mathrm{m}(B)$. 

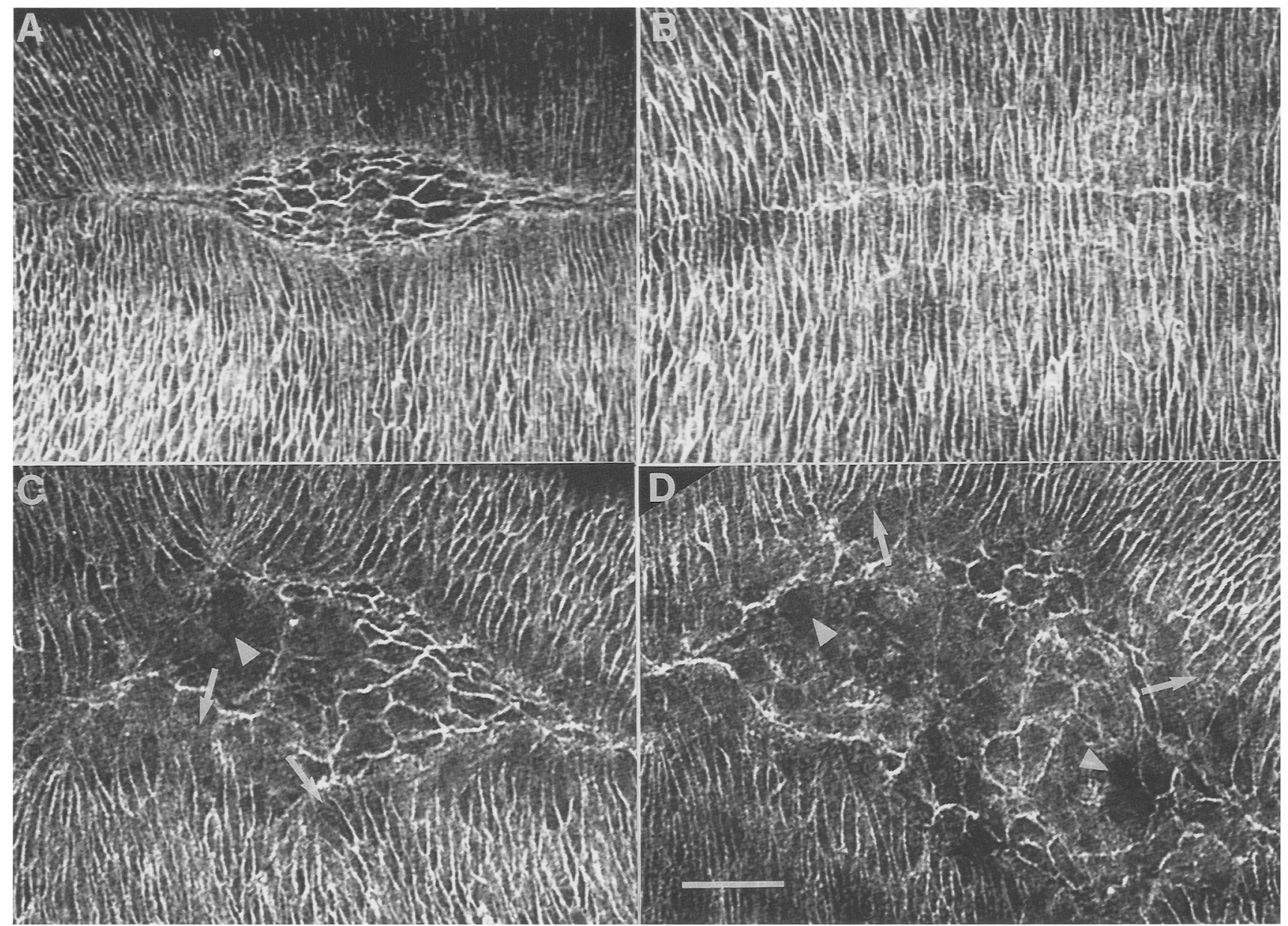

Figure 4. Cell shapes are perturbed in myosin mutants. Abnormal cell shapes in myosin mutants are shown in confocal fluorescent micrographs of whole-mount embryos, fixed and stained with anti-spectrin antiserum. $(A, B)$ Wild-type embryos; $(C, D)$ homozygous zip ${ }^{\text {mhc-c1.3 }}$ embryos. Identification of mutant embryos was by the absence of $\beta$-galactosidase, produced by a transgenic construct present on the wild-type balancer chromosome. Note the smoothness and organization of the leading edge in wild-type embryos $|A|$. In $B$, dorsal closure is complete, and the lateral epidermis on both sides of the embryo has fused along the dorsal midline. In homozygous zip embryos, the shapes of cells in the leading edge are aberrant and the organization of the leading edge is obliterated $(C, D)$. Dark patches in the confocal image (arrowheads) in $C$ and $D$, particularly in the region of the amnioserosa, indicate regions of the embryo that pass in and out of the optical plane of section. Arrows indicate ends of cells that are splayed apart. Bar in $D, 25 \mu \mathrm{m}$ (for $A-D$ ).

tispectrin at two stages during dorsal closure. At the beginning of dorsal closure the cells of the lateral epidermis are close to isodiametric / the ratio of cell diameters measured along the dorsal-ventral axis of the embryo divided by cell diameters measured along the anterior-posterior axis of the embryo is $1.5 ; n=300$ cells in three different embryos). At this stage, the lateral epidermis covers approximately one-third to one-half of the circumference of the embryo [measured at 50\% egg length (see Fullilove and Jacobson 1978), Figs. 33, 35-41). By the end of dorsal closure, the cells are, on average, much longer than they are wide / the ratio of diameters measured along the dorsal-ventral axis to the anterior-posterior axis of the embryo is $5.2 ; n=300$ cells in three different embryos). This change in cell dimension produces an epidermal sheet large enough to completely surround the circumference of the embryo.
Although dorsal closure fails in homozygous zip mutant embryos (which lack zygotically encoded wild-type myosin) and the leading edge is characterized by improper cell shape changes as documented above, cells of the lateral epidermis appear to elongate in a manner qualitatively similar to that observed in wild-type embryos (see Fig. 4). We hypothesize that this cell elongation is powered by the maternal myosin that perdures through early stages of dorsal closure and is visible at the leading edge of the lateral epidermis even in homozygous mutants (see Fig. 5). This is consistent with the fact that some dorsal closure does occur, that is, there is some dorsal displacement of the lateral epidermis over the amnioserosa in mutant embryos. By this hypothesis, dorsal closure finally fails because mutant myosin, which is zygotically encoded, fails to contribute sufficient myosin function to drive dorsal closure to completion. 

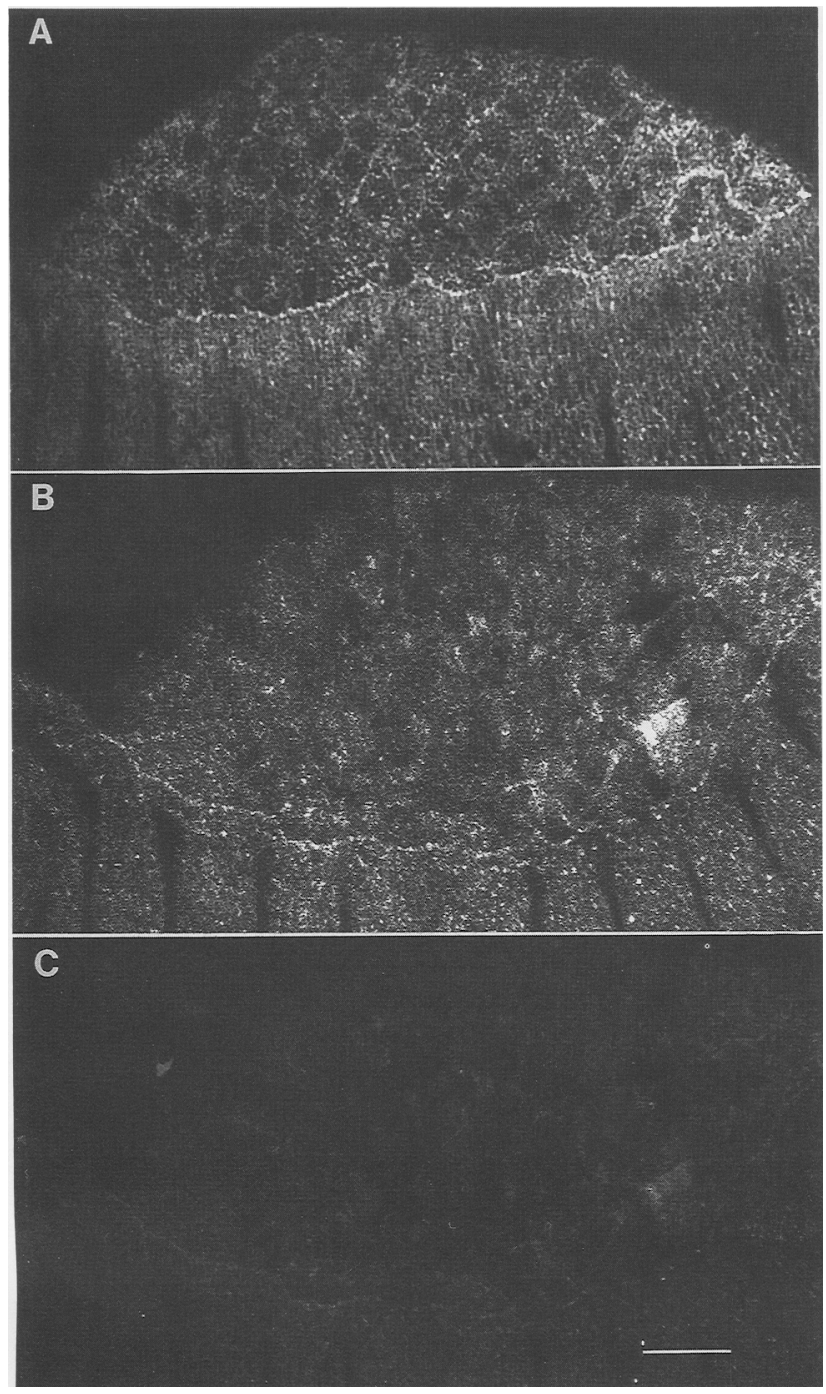

Figure 5. Early in dorsal closure, the pattern of myosin staining in zip embryos is normal, albeit at reduced levels. Confocal fluorescent micrographs of whole mount embryos fixed and stained with anti-nonmuscle myosin antiserum. (A) Wild-type embryo early in dorsal closure. Note that the pattern, which shows increased levels of diffuse staining in the cells of the leading edge and a specific targeting of myosin to the leading edge, is comparable to those seen in Fig. 3. $(B, C)$ Homozygous zip $^{\text {mhc-c1.3 }}$ embryo at a comparable stage in development. Because the overall level of myosin protein in the mutant homozygotes is reduced severely, the gain used to generate $B$ was increased to allow analysis of the pattern of myosin staining. The gain used to generate $C$ is comparable to that used to generate $A$. Although myosin staining is severely reduced in zip mutant embryos at early stages of dorsal closure, the targeting of myosin to the leading edge is qualitatively similar to that observed in wild-type embryos. Bar in $C, 25 \mu \mathrm{m}$ (for $A-C$ ).

\section{Discussion}

Nonmuscle myosin is a recessive, lethal locus required for Drosophila viability. We recover and characterize mutations in the gene that encodes the nonmuscle my- osin heavy chain polypeptide and demonstrate that severe alleles die as embryos. We show that these mutations fail to complement the previously described but molecularly uncharacterized zip mutations (NüssleinVolhard et al. 1984; also see below). Immunoblot analysis, DNA sequencing, and P-element-mediated rescues with myosin cDNA and genomic constructs demonstrate unambiguously that zip encodes the nonmuscle myosin heavy chain. These data demonstrate that zip does not encode a transmembrane protein as reported previously (Zhao et al. 1988; see below). To better understand how myosin participates in morphogenesis, we analyze cell shapes during dorsal closure and demonstrate that they are defective in myosin mutants.

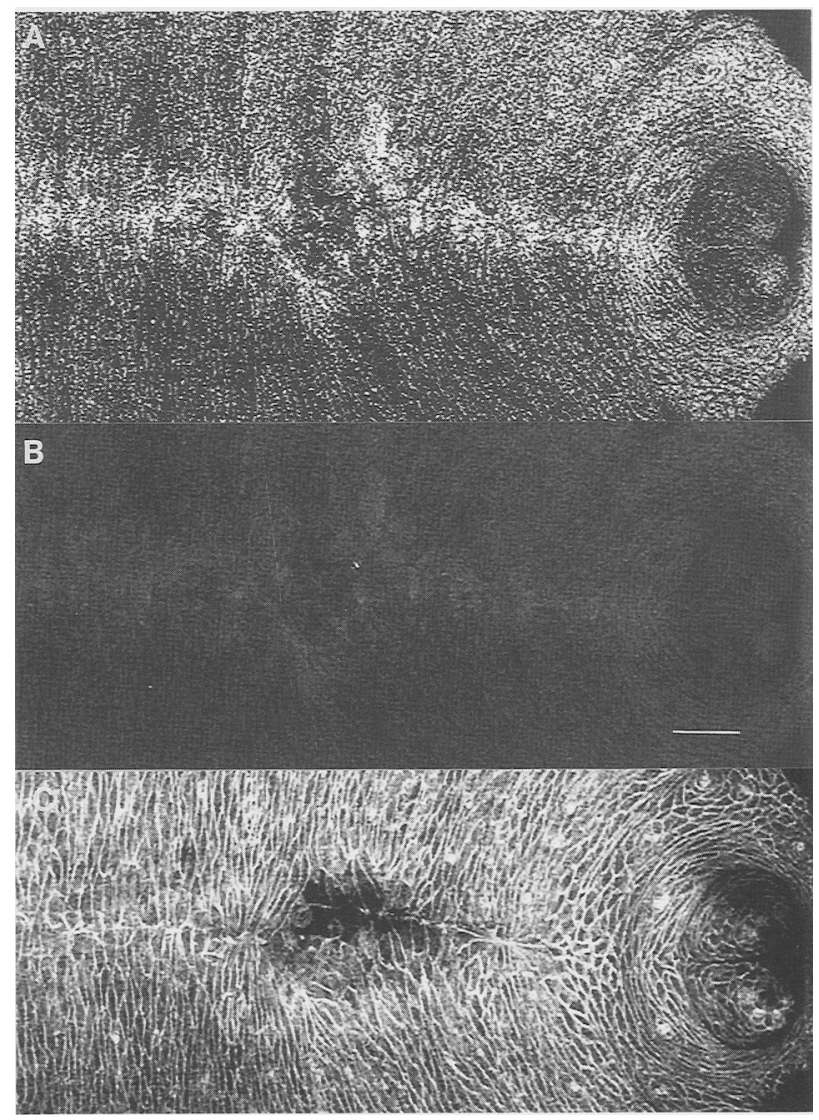

Figure 6. Late in dorsal closure, myosin is absent from the leading edge in zip mutants. Confocal fluorescent micrographs of a whole-mount, homozygous zip ${ }^{\text {mhc-c1.3 }}$ embryo double stained for myosin $(A, B)$ and spectrin $(C) .(A)$ Myosin is not properly targeted to the leading edge of the lateral epidermis in zip $^{\text {mhc-c1.3 }}$ embryos. No discrete line of staining, comparable to that documented in Figs. 3 or 5 is seen. As in Fig. 5, the gain has been increased to evaluate the pattern. (B) Same embryo as in $A$, with the gain comparable to that used in the generation of the images shown in Fig. 3. It depicts a substantial, overall reduction in the level of myosin across the entire embryo that is consistent with the low abundance of myosin seen in immunoblots of mutant embryos (see Fig. 1). (C) Same embryo shown in $B$, viewed on a channel that reveals anti-spectrin staining. It is provided for orientation. Bar in $B, 25 \mu \mathrm{m}$ (for $A-C$ ). 

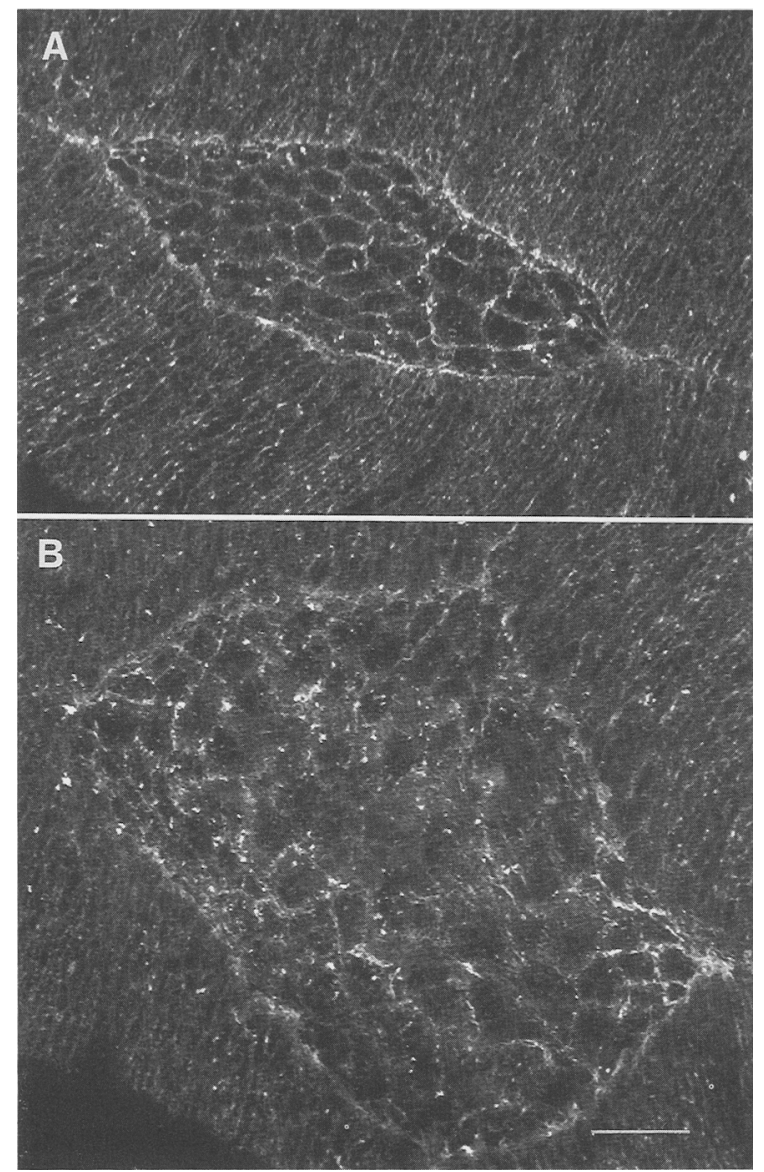

Figure 7. The distribution of actin during dorsal closure is the same in wild-type and zip mutant embryos. Fluorescent confocal micrographs of whole-mount embryos fixed and stained with anti-actin demonstrate that the distribution of actin is normal in zip homozygous embryos. $(A)$ Actin is targeted to the leading edge of the lateral epidermis in a wild-type embryo in a manner comparable to that seen for myosin in previous figures. $(B)$ The distribution of actin in zip embryos is quantitatively and qualitatively comparable to that seen in wild type, suggesting that actin can be targeted to the leading edge in the absence of myosin. The irregular shape of the exposed amnioserosa confirms aberrant dorsal closure in the zip mutant embryo. Bar in $B$, $25 \mu \mathrm{m}$.

\section{Myosin powers cell sheet morphogenesis}

The precise role of myosin in dorsal closure remains elusive. This movement, specifically, and cell sheet morphogenesis, generally, require a complex integration of interactions among individual cells that are changing shape. During dorsal closure, the epidermal cell sheet spreads to encircle the embryo and close at the dorsal midline. Individual cells change from polygonal to elongate while maintaining the integrity of the cell sheet. Low levels of myosin appear to be present in all cells; therefore, myosin may contribute in a cell autonomous fashion to the shape changes observed. However, the most conspicuous accumulation of myosin is at the lead- ing edge of the dorsal epithelium, and the integrity of this edge is obliterated in zip mutants at later stages of dorsal closure. Clearly, our observations demonstrate that myosin is at least required for the maintenance and stabilization of cell shapes during dorsal closure. However, given the role of myosin as a chemomechanical force producer in muscle, the colocalization of actin and myosin at the leading edge, and the function of myosin for cell shape change in cytokinesis, we speculate that myosin plays an active role in producing force for cell shape change during dorsal closure.

The tight correlation between myosin localization and cell elongation during dorsal closure suggests a model by which myosin contractility at the leading edge of the lateral epidermis powers this cell sheet movement during normal development. As dorsal closure begins, myosin is targeted to the leading edge of the lateral epidermis. This myosin can be maternally contributed: In homozygous zip mutants that fail to accumulate appreciable levels of zygotically encoded myosin, this early pattern is still conspicuous. As dorsal closure proceeds, cells elongate throughout the lateral epidermis, first the dorsal-most cells and progressively more ventral ones. In wild-type embryos, myosin staining at the leading edge persists through to the end of dorsal closure, when the lateral epidermis meets and fuses along the dorsal midline. However, in homozygous zip mutant embryos, myosin is no longer present at the leading edge toward the end of dorsal closure, the cells of the leading edge become aberrant in shape, and dorsal closure fails.

The simplest model that accommodates these observations envisions myosin (and actin) in a mechanically contiguous contractile band, or purse string composed of a series of intracellular contractile rings or plates positioned at the leading edge of the lateral epidermis (diagramed in Fig. 2; also see localization of myosin in Fig. $3 \mathrm{C}$ and of actin in Fig. 7). The mechanical integrity of the epidermal sheet requires strong intercellular connections, mediated through cellular junctions and the extracellular matrix. Because the amnioserosa and the tissue beneath it defends its volume, shortening of this bandmediated by actomyosin contractility-would serve to draw the lateral epidermis toward the dorsal surface of the embryo and thereby effect dorsal closure. The dorsal movement of the lateral epithelia would be akin to the movement of a velvet purse, drawn closed by a purse string, over a billiard ball. In this manner, the function of myosin during dorsal closure would parallel its function during cytokinesis, where an intracellular purse string is believed to power cell shape change. Moreover, this form of sheet morphogenesis, driven by apical constriction of individual epithelial cells, would be mechanistically comparable with the cell shape changes that have been proposed to underlie other cell sheet shape changes, for example, neural tube formation in vertebrates (Burnside 1971) and gastrulation in fly (Young et al. 1991). The main value of this model is that it makes specific predictions that are, in principle, readily testable. For example, if correct, disruption of the integrity of the lateral epidermis by microsurgery or laser ablation studies 

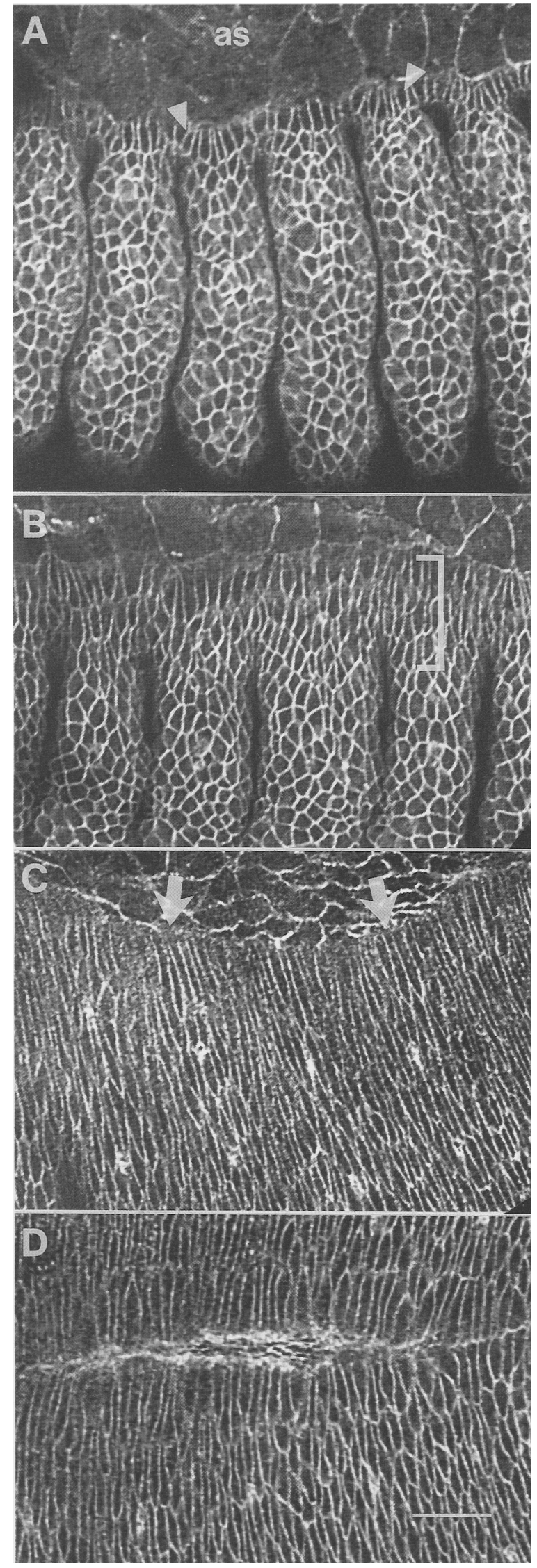

should have profound consequences on the progression of dorsal closure in wild type embryos. In this model shape change in a vast majority of the individual cells of the lateral epithelium is passive, with force produced by myosin contractility in cells at the leading edge. To understand in detail how myosin functions for these cell shape changes, we require a precise understanding of where force is generated and how it is transmitted.

Interestingly, embryogenesis appears to proceed normally in homozygous zip mutants until dorsal closure stages. Movements such as cellularization and gastrulation, for which some functional evidence (Kiehart et al. 1990) and good circumstantial evidence (Young et al. 1991) suggest an active role for myosin in cell shape change, occur normally in the absence of zygotically encoded wild-type myosin. Such shape changes are likely powered by the maternal myosin that perdures in these embryos. Previously, we showed that unfertilized eggs contain substantial amounts of myosin heavy chain (Young et al. 1991). Immunoblots of homozygous zip embryos are consistent with perdurance of maternal myosin into dorsal closure stages. Moreover, the observations that myosin accumulates to high levels in the cells of the leading edge, and that defects in the morphology of the leading edge characterize zip mutations, suggest that it is in these cells that zygotically encoded myosin heavy chain is first required.

\section{Drosophila nonmuscle myosin and cytokinesis}

Previous studies (Mabuchi and Okuno 1977; Kiehart et al. 1982; De Lozanne and Spudich 1987; Knecht and Loomis 1987; Karess et al. 1991) have unambiguously demonstrated a role for myosin in cell shape changes during cytokinesis in various organisms. However, we have not observed obvious defects in cytokinesis in homozygous zip embryos. This result is not surprising, in light of the maternal contribution of myosin to the egg and the observation that most embryonic cell divisions have been completed before dorsal closure (Hartenstein and Campos-Ortega 1985; Technau and Campos-Ortega 1986; Foe 1989). Clearly, maternal myosin stores may permit cytokinesis to occur normally in the early embryo. Cytokinetic defects may characterize zip mutants in isolated groups of cells that undergo mitosis at later

Figure 8. Cell sheet morphogenesis is accompanied by changes in cell shape. Confocal fluorescent micrographs of wholemount, wild-type embryos, fixed and stained with anti-spectrin antiserum. $(A-C)$ Optical, en face sections of different embryos, fixed at progressively later times during dorsal closure; $D$ a more dorsal optical en face section of a different embryo, fixed just before the completion of dorsal closure. Arrowheads indicate elongated cells at the leading edge in $A$. The bracket in $B$ reveals the increasing extent of the zone of elongated cells. Arrows indicate the smoothness of the leading edge of the advancing lateral epidermis in C. (as) Amnioserosa. Bar in $D, 25 \mu \mathrm{m}$ (for $A-D)$. 
stages, but we have not focussed on identifying such events.

Interestingly, the terminal phenotype of mutations in the myosin heavy chain and light chain is distinct. The heavy chain, encoded by zip, and the regulatory light chain, encoded by sqh (Karess et al. 1991; X.-J. Chang, K.A. Edwards, R.F. Karess, S. Kulkarni, I. Aguilera, and D.P. Kiehart, unpubl.), are subunits of the same, native, nonmuscle myosin isoform and coordinately function to effect contractility. Whereas severe zip mutations fail at embryonic dorsal closure stages, $s q h^{1}$ mutants complete embryogenesis but arrest during third-instar larval stages with defects in cytokinesis (Karess et al. 1991). The differences observed in the terminal phenotypes of the $s q h^{1}$ and the zip alleles that we characterize here may be due simply to the observation that the single, existing allele of $s q h, s q h^{1}$, is not null. Alternatively, different patterns of myosin heavy chain and regulatory light chain transcription, translation, and protein turnover may explain these phenotypic differences. Moreover, it is possible that homozygotes of weak zip alleles may have a phenotype of arrest comparable to $s q h^{1}$ homozygotes.

\section{Myosin is required for other developmental processes}

Nonmuscle myosin is a conspicuous component of Drosophila cells and tissues throughout development (Fig. 1A; Kiehart et al. 1989; Young et al. 1991), where it presumably plays a critical role in maintaining or changing cell shape. Preliminary immunofluorescent localization data (not shown) confirm our suspicion that the distribution of this protein is widespread, as it is in vertebrates (e.g., Korn and Hammer 1988; Kawamoto and Adelstein 1991). Moreover, this myosin is required for later development. Two weak zip alleles die after embryo hatching, but before eclosion, and a single heat shock rescues embryos (homozygous for severe zip alleles), transformed with an appropriate myosin heavy chain cDNA construct (see Results), to first instar larvae that subsequently fail to molt without additional expression of wild-type myosin heavy chain.

Nonmuscle myosin is also localized in the Drosophila embryonic nervous system (Young et al. 1991). Myosin and actin are conspicuous components of nerve growth cones from Drosophila (S.G. Mansfield and D.P. Kiehart, unpubl.) and other species as well (Forscher and Smith 1988; Bridgman and Dailey 1989), and cytochalasins can disrupt axon pathfinding in grasshopper embryos (Bentley and Toroian-Raymond 1986; Miller et al. 1992). Homozygous $z i p^{m h c-c 1.3}$ and $z i p^{I I F 107} / z^{\text {minc-c1.3 }}$ transheterozygous embryos have defects in axon patterning (data not shown) identical to the defects observed previously for zip ${ }^{I I F 107}$ and zip ${ }^{I D 16}$ mutant embryos (Côté et al. 1987; Zhao et al. 1988). Clearly, these data suggest that myosin plays a role in growth cone motility and/or in maintaining the epithelia on which the growth cones migrate.

It is clear that imaginal disc morphogenesis, as during dorsal closure, depends on cell shape changes (Condic et al. 1991). Evidence from clonal analysis experiments shows that lesions in eye, wing, and abdominal tissue occur in clonal patches that are homozygous for strong zip alleles, demonstrating that nonmuscle myosin is required for imaginal development (D.P. Kiehart and P.E. Young, unpubl.). In addition, recent experiments by J. Fristrom and P. Gotwals (unpubl.), performed in collaboration with our laboratory, indicate that a previously identified mutation, Enhancer of broad $[E(b r)]$ is also a zip allele. The $E(b r)$ mutation was identified because of its role in ecdysone-dependent disc morphogenesis (Gotwals and Fristrom 1991), thereby providing additional support for a function for nonmuscle myosin in imaginal disc development.

\section{unzipped}

A previously published report claims to have cloned molecularly the DNA that encodes the zip locus (Zhao et al. 1988). The transcription unit that it assigns to zip is adjacent, in the fly genome, to the transcription unit that encodes the nonmuscle myosin heavy chain gene. But the data are circumstantial, based on the pattern of expression of the cloned transcription unit and the observed neurological phenotype. No defects in the transcription, protein accumulation, or protein sequence of this transmembrane protein have yet been identified in zip mutants (S. Côté and J. Plante, pers. comm.). The observed defects in the myosin heavy chain polypeptide and our ability to rescue zip mutations with the wildtype myosin cDNA prove that zip encodes myosin and not the low-molecular-weight integral membrane protein described previously. To avoid confusion, we suggest [and Côté and Jäckle concur (pers. comm.)] that the previously named zip protein, which is unrelated either to the zip gene or to the myosin heavy chain that zip encodes, should now be called unzipped, with uzi as an appropriate abbreviation.

\section{Myosin and cell shape change}

Presumably, myosin participates in the morphogenic movements of a wide range of species including vertebrates by a mechanism that parallels its involvement in dorsal closure. The cell sheet movements that we detail in this paper are reminiscent, for example, of the process of epiboly in teleost and avian development. Consistent with this idea, early morphological studies (Betchaku and Trinkaus 1978) document a distribution of microfilaments at the leading regions of cell sheets during epiboly that is similar to the accumulation of myosin that we observe at the leading edge of the lateral epidermis. Pharmacological studies (Trinkaus and Drake 1956; Betchaku and Trinkaus 1978) using cytochalasin B and EGTA prompted researchers to suggest that microfilaments and myosin, specifically, might be actively involved in driving epiboly. The results of our mutational analysis of myosin function in Drosophila lend credence to such a hypothesis.

The similarity in the localization of myosin for cellularization, gastrulation, and dorsal closure in Droso- 
phila, and the absolute requirement of myosin for cytokinesis and dorsal closure lead us to speculate (1) that cytokinesis is simply a specialized form of cell shape change, and (2) that the three processes of cell shape change depend on a single, underlying molecular mechanism for which myosin is the chemomechanical force producer.

\section{Materials and methods}

\section{Drosophila strains}

Mutagenesis experiments were performed on a $d p c n b w$ stock recently isogenized for chromosome 2 . Wild-type flies were of the Canton-S strain. To verify the genotype of progeny of heterozygous parental crosses, the balancer chromosome was marked with a $\beta$-galactosidase ( $\beta$-gal) construct driven by a promoter active during embryogenesis. Homozygous mutant embryos lacked significant $\beta$-gal staining compared with heterozygotes or homozygous balancer siblings. The balanced deficiency stocks, $D f(2 R) E S 1, D f(2 R) I I X 62$, and $D f(2 R) S B 1$, and the balanced mutant stocks, zip ${ }^{I I F 107} / \mathrm{CyO}$ and $z i p^{I D 16} / \mathrm{CyO}$ were all generous gifts of Serge Côté (descriptions of these strains are in Nüsslein-Volhard et al. 1984; Côté et al. 1987).

\section{Antibodies}

Polyclonal antisera directed against Drosophila nonmuscle (cytoplasmic) myosin and Drosophila spectrin were described previously (Kiehart and Feghali 1986; Byers et al. 1987; Pesacreta et al. 1989; Young et al. 1991). Antiserum directed against horseradish peroxidase was obtained commercially (Sigma; St. Louis, $\mathrm{MO}$. An antiserum directed against bacterial $\beta$-gal was the generous gift of Robert Holmgren (Northwestern University, Evanston, IL).

\section{EMS mutagenesis}

To generate mutations in the gene that encodes nonmuscle myosin heavy chain, we mutagenized $d p c n b w$ flies with EMS by standard methods (Lewis and Bascher 1968). To resolve germline mosaics, we crossed mutagenized flies to a balancer stock using a protocol that avoids recovering clusters that result from the mutagenesis of premeiotic germ cells. To recover mutations that map at or near the mhc-c locus, individual mutagenized males were crossed to $D f(2 R) E S 1$ If/CyO virgin females. Balanced $(d p \mathrm{cn} b w / C y O)$ stocks of potential interest were recovered from crosses that failed to give individuals of the genotype $d p$ cn $b w / D f(2 R) E S 1$ If. We verified that $D f(2 R) E S 1$ removes the mhc-c locus by quantitative Southern blot analysis. We screened $\sim 3000$ mutagenized chromosomes, 1500 at $29^{\circ} \mathrm{C}$, in an attempt to recover temperature-sensitive mutations. Complementation analysis was by inter se crosses of all recovered alleles.

\section{Molecular biological methods and Southern blot analysis}

Molecular biological techniques were performed by standard methods (Sambrook et al. 1989). EcoRl-digested genomic DNA was resolved by agarose gel electrophoresis and blotted to ZetaProbe (Bio-Rad, Richmond, CA) by the method of Church and Gilbert (1984). Fragments of interest were detected using a ra- diolabeled, full-length mhc-c cDNA probe (Kiehart et al. 1989; Ketchum et al. 1990).

\section{Immunoblots and sample preparation}

Adult fly proteins were prepared for SDS-PAGE by homogenizing adults in phosphate-buffered saline [containing $0.05 \%$ saponin, $0.05 \%$ Triton X-100, 0.05\% N-P-40 $(\sim 1$ fly $/ 5 \mu l$ buffer $)]$; and centrifuging the homogenate at $13,000 g_{\max }$ for $2-3 \mathrm{~min}$ to remove insoluble (see below) myosin and other debris. The supernatant was mixed with an equal volume of $2 \times$ sample buffer and electrophoresed and blotted by standard methods described elsewhere (Kiehart and Feghali 1986; Young et al. 1991). Empirically, we found that under those conditions little or no muscle myosin was extracted and little or no nonmuscle myosin remained in the insoluble pellet; thus, interference due to the high concentration of muscle myosin ordinarily in the whole fly protein samples was eliminated. Individual or small numbers of embryos were homogenized directly in $1 \times$ sample buffer and processed as described above. To evaluate relative levels of protein in sets of samples, blots were also stained with antispectrin. Even in zip mutants that completely lacked myosin, spectrin levels were essentially identical to those seen in controls.

\section{Immunofluorescence}

Antibody labeling and confocal microscopy of embryos were as described previously (Young et al. 1991). Cell shape was observed by immunofluorescent stains of embryos with antispectrin (Pesacreta et al. 1989; Schweisguth et al. 1990).

\section{P-element-mediated rescue}

A cDNA that includes the predominant (shorter) protein-coding sequence of the Drosophila cytoplasmic myosin heavy chain (Ketchum et al. 1990) was subcloned into the EcoRI site of the pCaSpeR-heat shock vector (Capovilla et al. 1992). This vector was constructed by V. Pirrotta and C. Thummel /electronic reference is Dros. Inf. Newsl. vol. 2, April 1991) and contains the hsp70 promoter (from nucleotide -245 to the $X m n I$ site at +207 in a gene at $87 \mathrm{Cl}$; see Ignolia et al. 1980) and 3' untranslated sequence from the $h s p 70$ gene [excised as a 525-bp EcoRIPst fragment from pHT4 (Schneuwly et al. 1987) in a gene at 87A7] cloned into pCaSpeR (Pirrotta 1988). A full-length cDNA and flanking vector DNA in pNB40 (Ketchum et al. 1990) was subcloned into pUC19, SacI was used to generate a 3 ' overhang protected end, unidirectional deletion by exonuclease III digestion was used to generate a family of clones with different $5^{\prime}$ ends, overhangs were trimmed with S1 nuclease and filled in with Klenow fragment, and blunt ends were religated. Clones were picked and their $5^{\prime}$ ends were sequenced. A clone that included the EcoRI site and 4 nucleotides from pUC19 (GAATTCGAGCl, 5 myosin codons $5^{\prime}$ of the translation start ATG, the entire myosin coding region, $188 \mathrm{bp}$ of myosin $3^{\prime}$-untranslated sequence up to a short stretch of poly(A), and $30 \mathrm{bp}$ of pNB40 sequence to a cloning EcoRI site was subcloned into the EcoRI site of the polylinker of the $\mathrm{pCaSpeR}$-heat shock vector. Proper orientation of the inserted DNA was determined by using restriction enzyme digests. The construct DNA was purified from a large scale cesium chloride preparation as described by Sambrook et al. (1989). The DNA was resuspended in injection buffer [ $5 \mathrm{mM} \mathrm{KCl}, 0.1 \mathrm{~mm}$ potassium phosphate $(\mathrm{pH} 7.8)]$ to a final concentration of $0.5 \mathrm{mg} / \mathrm{ml}$. The construct was transformed into the germ line of $w$; delta 2-3 flies (Robertson et al. 1988) by standard methods (Ashburner 1989). One transformant line was selected and used for rescue experiments. 
The structure of that portion of the fly genome that spans the zip and uzi transcription units was gleaned from published restriction maps (Kiehart et al. 1989; Côté et al. 1987), Southern blots with appropriate zip and uzi probes (data not shown), and a PCR experiment (described below). A molecular map of the region appears in Figure 2 of Côté et al. (1987), which fails to describe properly the location of the zip locus. Their location of zip is the location of uzi. The $5^{\prime}$ end of the zip transcript is located at coordinate -47 on the map of Côté et al. and extends $21 \mathrm{~kb}$ to beyond the -60 coordinate. Thus, the transcription start for zip is $\sim 10 \mathrm{~kb}$ from the start site of $u z i$, and the two genes are transcribed in opposite directions.

A cosmid that includes the entire myosin (zip) transcription unit in the vector pCoSpeP was recovered from a library constructed and kindly provided by John Tamkun (University of California, Santa Cruz). The cosmid has an $\sim 35-\mathrm{kb}$ insert that extends $\sim 2 \mathrm{~kb} \mathrm{5}$ ' of the transcription start and $11.5 \mathrm{~kb} \mathrm{3}$ ' of the poly $(A)$ addition sites. We confirmed that this construct cannot encode the uzi gene product using a PCR strategy. Primers in the $5^{\prime}$ end of the uzi protein-coding region were based on $u z i$ sequence kindly provided by Serge Côté and failed to produce PCR product when purified cosmid DNA was used as a template. In contrast, myosin (zip) primers made product of the expected size on the same cosmid template, and the uzi primers made product on purified ES26 DNA, also kindly provided by Serge Côté.

\section{Acknowledgments}

We wish to thank S. Côté for generous gifts of DNA clones, fly stocks, and helpful discussions throughout this research; V. Hartenstein for generously sharing his computer-drawn sketches of the fly embryo during dorsal closure stages; K.A. Edwards for performing the PCR experiments that mapped the $5^{\prime}$ end of the rescue cosmid; M. Farzan for his computer program, CELLSIZE; M. Mortin, W. Gelbart, L.S.B. Goldstein, F. Kafatos, R. Ray, V. Twombly, and various members of the Gelbart and Kafatos laboratories for help with the intricacies of Drosophila genetics; L.S.B. Goldstein for redirecting our consideration of the zip mutants; C. Goodman, C. Nüsslein-Volhard, E. Wieschaus, J. Fristrom, D. Fristrom, and N. Perrimon for insights into various zip phenotypes; S. Bray for assistance with anti- $\beta$-gal antibody and helpful suggestions regarding secondary antibodies; L. Lucas, D. Lucas, M. Kordylewski, and J. Gargano for their help in the Biolabs Drosophila facility; S. Counce, S.G. Mansfield, and R. Ray for critical reading of sections of the manuscript; J. Salant and R. Montague for help in the preparation of the manuscript; and M. Shea, G. Thomas, K. Edwards, X-J. Chang, T-L. Chen, and M. McDowell for stimulating discussions and suggestions. We also thank P. Gotwals and J. Fristrom for sharing unpublished data on $E(b r)$, S. Côté for unpublished data on his genomic walk at $60 \mathrm{E}, \mathrm{F}$, and S. Côté and $\mathrm{H}$. Jäckle for allowing us to suggest a new name, unzipped or $u z i$, for the protein that they and their co-workers had inadvertently identified as the zip gene product. Finally, D.P.K. thanks Ray Erikson and Rich Losick for their continued interest in and support of our work. This work was supported by a grant from the National Institutes of Health (GM33830, to D.P.K.) and a National Science Foundation predoctoral fellowship (to P.E.Y.), and is to be submitted in partial fulfillment of requirements for a Ph.D. degree in Cellular and Developmental Biology at Harvard University.

The publication costs of this article were defrayed in part by payment of page charges. This article must therefore be hereby marked "advertisement" in accordance with 18 USC section 1734 solely to indicate this fact.

\section{References}

Armstrong, P.B. 1985. The control of cell motility during embryogenesis. Cancer Metastasis Rev. 4: 59-80.

Ashburner, M. 1989. Drosophila: A laboratory handbook. Cold Spring Harbor Laboratory Press, Cold Spring Harbor, New York.

Bentley, D. and A. Toroian-Raymond. 1986. Disoriented pathfinding by pioneer neural growth cones deprived of filopodia by cytochalasin treatment. Nature 323: 712-715.

Betchaku, T. and J.P. Trinkaus. 1978. Contact relations, surface activity, and cortical microfilaments of marginal cells of the enveloping layer and of the yolk syncytial and yolk cytoplasmic layers of Fundulus before and during epiboly. I. Exp. Zool. 206: 381-426.

Bridgman, P.C. and M.E. Dailey. 1989. The organization of myosin and actin in rapid frozen nerve growth cones. $J$. Cell Biol. 108: 95-109.

Burnside, B. 1971. Microtubules and microfilaments in newt neurulation. Dev. Biol. 26: 416-441.

Byers, T.J., R. Dubreuil, D. Branton, D.P. Kiehart, and L.S.B. Goldstein. 1987. Drosophila spectrin. II. Conserved features of the $\alpha$-subunit are revealed by analysis of cDNA clones and fusion proteins. I. Cell Biol. 105: 2103-2110.

Campos-Ortega, J.A. and V. Hartenstein. 1985. The embryonic development of Drosophila melanogaster. Springer-Verlag, Heidelberg, Germany.

Capovilla, M., E.D. Eldon, and V. Pirrotta. 1992. The giant gene of Drosophila encodes a b-ZIP DNA-binding protein that regulates the expression of other segmentation gap genes. Development 114: 99-112.

Church, G.M. and W. Gilbert. 1984. Genomic sequencing. Proc. Natl. Acad. Sci. 81: 1991-1995.

Condic, M.L., D. Fristrom, and J.W. Fristrom. 1991. Apical cell shape changes during Drosophila imaginal leg disc elongation: A novel morphogenetic mechanism. Development 111: 23-33.

Côté, S., A. Preiss, J. Haller, R. Schuh, A. Kienlin, E. Seifert, and H. Jäckle. 1987. The gooseberry-zipper region of Drosophila: Five genes encode different spatially restricted transcripts in the embryo. EMBO J. 6: 2793-2801.

De Lozanne, A. and J. Spudich. 1987. Disruption of the Dictyostelium myosin heavy chain gene by homologous recombination. Science 236: 1086-1091.

Ettensohn, C.A. 1985. Mechanisms of epithelial morphogenesis. Q. Rev. Biol. 60: 289-307.

Fessler, J.H. and L.I. Fessler. 1989. Drosophila extracellular matrix. Annu. Rev. Cell Biol. 5: 309-339.

Foe, V.E. 1989. Mitotic domains reveal early commitment of cells in Drosophila embryos. Development 107: 1-22.

Forscher, P. and S.J. Smith. 1988. Actions of cytochalasins on the organization of actin filaments and microtubules in a neuronal growth cone. J. Cell Biol. 107: 1505-1516.

Fristrom, D. 1988. The cellular basis of epithelial morphogenesis. A review. Tissue \& Cell 20: 645-690.

Fullilove, S.L. and A.G. Jacobson. 1971. Nuclear elongation and cytokinesis in Drosophila montana. Dev. Biol. 26: 560-577.

Gotwals, P.J. and J.W. Fristrom. 1991. Three neighboring genes interact with the broad-complex and the stubble-stubbloid locus to affect imaginal disc morphogenesis in Drosophila. Genetics 127: 747-759.

Hartenstein, V. and J.A. Campos-Ortega. 1985. Fate-mapping in wild type Drosophila melanogaster. I. The spatio-temporal pattern of embryonic cell divisions. Wilhelm Roux's Arch. Dev. Biol. 194: 181-195.

Ignolia, T.D., E.A. Craig, and B.J. McCarthy. 1980. Sequence of 
three copies of the gene for the major Drosophila heat induced protein and their flanking regions. Cell 21: 669-679.

Karess, R.E., X.-J. Chang, K.A. Edwards, S. Kulkarni, I. Aguilera, and D.P. Kiehart. 1991. The regulatory light chain of nonmuscle myosin is encoded by spaghetti-squash, a gene required for cytokinesis in Drosophila. Cell 65: 1177-1189.

Kawamoto, S. and R.S. Adelstein. 1991. Chicken nonmuscle myosin heavy chains: Differential expression of two mRNAs and evidence for two different polypeptides. J. Cell Biol. 112: 915-924.

Ketchum, A.S., C.T. Stewart, M. Stewart, and D.P. Kiehart. 1990. Complete sequence of the Drosophila nonmuscle myosin heavy chain transcript: Conserved sequences in the myosin tail and differential splicing in the $5^{\prime}$ untranslated sequence. Proc. Natl. Acad. Sci. 87: 6316-6320.

Kiehart, D.P. 1990. Molecular genetic dissection of myosin heavy chain function. Cell 60: 347-350.

Kiehart, D.P. and R. Feghali. 1986. Cytoplasmic myosin from Drosophila melanogaster. J. Cell Biol. 103: 1517-1525.

Kiehart, D.P., I. Mabuchi, and S. Inoue. 1982. Evidence that myosin does not contribute to force production in chromosome movement. J. Cell Biol. 94: 165-178.

Kiehart, D.P., M.S. Lutz, D. Chan, A.S. Ketchum, R. Laymon, B. Nguyen, and L.S.B. Goldstein. 1989. Identification of the gene for fly non-muscle myosin heavy chain: Drosophila myosin heavy chains are encoded by a gene family. EMBO J. 8: 913-922.

Kiehart, D.P., A. Ketchum, P. Young, D. Lutz, M.R. Alfenito, X.-J. Chang, M. Awobuluyi, T.C. Pesacreta, S. Inoue, C.T. Stewart, and T.-L. Chen. 1990. Contractile proteins in Drosophila development. Ann. NY Acad. Sci. 582: 233-25l.

Knecht, D.A. and W.F. Loomis. 1987. Antisense RNA inactivation of myosin heavy chain gene expression in Dictyostelium discoideum. Science 236: 1081-1086.

Korn, E.D. and J.A. Hammer III. 1988. Myosins of nonmuscle cells. Annu. Rev. Biophys. Biophys. Chem. 17: 23-45.

Letourneau, P.C., T.A. Shattack, and A.H. Ressler. 1987. "Pull" and "push" in neurite elongation: Observations on the effects of different concentrations of cytochalasin B and Taxol. Cell Motil. Cytoskel. 8: 193-209.

Lewis, E.B. and F. Bascher. 1968. Method of feeding ethyl methane sulfonate (EMS) to Drosophila males. Dros. Inf. Serv. 43: 193.

Lindsley, D.L. and G.G. Zimm. 1992. The genome of Drosophila melanogaster. Academic Press, New York.

Mabuchi, I. and M. Okuno. 1977. The effect of myosin antibody on the division of starfish blastomeres. J. Cell Biol. 74: 251263.

Miller, M., E. Bower, P. Levitt, D. Li, and P.D. Chantler. 1992. Myosin II distribution in neurons is consistent with a role in growth cone motility but not synaptic vesicle mobilization. Neuron 8: 25-44.

Nüsslein-Volhard, C., E. Wieschaus, and H. Kluding. 1984. Mutations affecting the pattern of the larval cuticle in Drosophila melanogaster. I. Zygotic loci on the second chromosome. Wilhelm Roux's Arch. Dev. Biol. 193: 267-282.

Pesacreta, T.C., T.J. Byers, R. Dubreuil, D.P. Kiehart, and D. Branton. 1989. Drosophila spectrin: The membrane skeleton during embryogenesis. J. Cell Biol. 108: 1697-1709.

Pirrotta, V. 1988. Vectors for P-element transformation in Drosophila. In Vectors: A survey of molecular cloning vectors and their uses (ed. R.L. Rodriguez and D.T. Denhardt), Butterworths, Boston, MA.

Priess, J.R. and D.I. Hirsh. 1986. Caenorabditis elegans morphogenesis: The role of the cytoskeleton in the elongation of the embryo. Dev. Biol. 117: 156-173.
Robertson, H.M., C.R. Preston, R.W. Phillis, D.M. JohnsonSchlitz, W.K. Benz, and W.R. Engels. 1988. A stable genomic source of P-element transposase in Drosophila melanogaster. Genetics 118: 461-470.

Sambrook, J., E.F. Fritsch, and T. Maniatis. 1989. Molecular cloning: A laboratory manual. Cold Spring Harbor Laboratory Press, Cold Spring Harbor, New York.

Schweisguth, F., J.-A. Lepesant, and A. Vincent. 1990. The serendipity alpha gene encodes a membrane-associated protein required for the cellularization of the Drosophila embryo. Genes \& Dev. 4: 922-931.

Schneuwly, S., R. Klemenz, and W.J. Gehring. 1987. Redesigning the body plan of Drosophila by ectopic expression of the homeotic gene Antennapedia. Nature 325: 816-818.

Spudich, J.A. 1989. In pursuit of myosin function. Cell Regulation 1: 1-11.

Technau, G.M. and J.A. Campos-Ortega. 1986. Lineage analysis of transplanted individual cells in embryos of Drosophila melanogaster. II. Commitment and proliferation capabilities of neural and epidermal cell progenitors. Wilhelm Roux's Arch. Dev. Biol. 195: 445-454.

Trinkaus, J.P. and J.W. Drake. 1956. Exogenous control of morphogenesis in isolated Fundulus blastoderms by nutrient chemical factors. J. Exp. Zool. 132: 311-348.

Warrick, H.M. and J.A. Spudich. 1987. Myosin structure and function in cell motility. Annu. Rev. Cell Biol. 3: 379-421.

Watt, F.Z., G. Shiels, and E. Orr. 1987. The yeast MYO1 gene encoding a myosin-like protein required for cell division. EMBO J. 6: 3499-3505.

Young, P.E., T.C. Pesacreta, and D.P. Kiehart. 1991. Dynamic changes in the distribution of cytoplasmic myosin during Drosophila embryogenesis. Development 111: 1-14.

Zhao, D.-B., S. Côté, F. Jahnig, J. Haller, and H. Jäckle. 1988. Zipper encodes a putative integral membrane protein required for normal axon patterning during Drosophila neurogenesis. $E M B O$ I. 7: 1115-1119. 


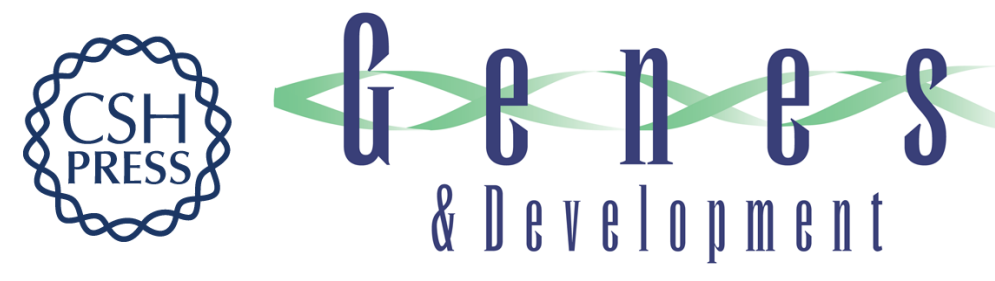

\section{Morphogenesis in Drosophila requires nonmuscle myosin heavy chain function.}

P E Young, A M Richman, A S Ketchum, et al.

Genes Dev. 1993, 7:

Access the most recent version at doi:10.1101/gad.7.1.29

References This article cites 47 articles, 19 of which can be accessed free at:

http://genesdev.cshlp.org/content/7/1/29.full.html\#ref-list-1

\section{License}

Email Alerting

Service

Receive free email alerts when new articles cite this article - sign up in the box at the top right corner of the article or click here.

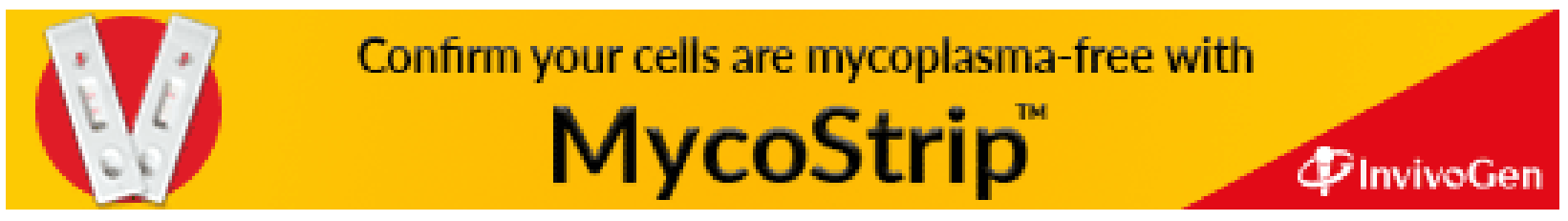

